\title{
Hydrogen Embrittlement Mechanism in Fatigue of Austenitic Stainless Steels
}

\author{
YUKITAKA MURAKAMI, TOSHIHIKO KANEZAKI, YOJI MINE, \\ and SABURO MATSUOKA
}

\begin{abstract}
The basic mechanism of the hydrogen embrittlement (HE) of stainless steels under fatigue loading is revealed as microscopic ductile fracture, resulting from hydrogen concentration at crack tips leading to hydrogen-enhanced slip. Fatigue crack growth rates in the presence of hydrogen are strongly frequency dependent. Nondiffusible hydrogen, at a level of 2 to approximately $3 \mathrm{wppm}$, is contained in ordinarily heat-treated austenitic stainless steels, but, over the last 40 years, it has been ignored as the cause of HE. However, it has been made clear in this study that, with decreasing loading frequency down to the level of $0.0015 \mathrm{~Hz}$, the nondiffusible hydrogen definitely increases fatigue crack growth rates. If the nondiffusible hydrogen at $\mathrm{O}$-sites of the lattice is reduced to the level of $0.4 \mathrm{wppm}$ by a special heat treatment, then the damaging influence of the loading frequency disappears and fatigue crack growth rates are significantly decreased.
\end{abstract}

DOI: $10.1007 / \mathrm{s} 11661-008-9506-5$

(C) The Minerals, Metals \& Materials Society and ASM International 2008

\section{INTRODUCTION}

THE objective of this article is to elucidate the basic principles of hydrogen embrittlement (HE) in the fatigue of austenitic stainless steels. These steels are considered to be the most important candidate materials for infrastructure, from the standpoint of the safe future of the hydrogen society (or hydrogen economy), as well as for components of fuel cell vehicles (FCVs) and stationary fuel cell (SFC) systems.

The materials used for the components of FCVs and SFCs and for the equipment for hydrogen stations, hydrogen pipelines, and transport systems are directly exposed to high-pressure hydrogen. Among these technologies, there has been a particularly difficult scientific problem termed "HE" in the presence of hydrogen.

During the past 40 years, many articles have been published on HE. Although the term HE has been widely used to describe the phenomenon, no unifying theory has been established. The mechanism of $\mathrm{HE}$ is still a mystery. The decohesion model ${ }^{[1,2]}$ is based on the theoretical calculation of the weakening of the lattice

YUKITAKA MURAKAMI, Trustee, Kyushu University, is Director, Research Center for Hydrogen Industrial Use and Storage (HYDROGENIUS), National Institute of Advanced Industrial Science and Technology (AIST). Contact e-mail: ymura@mech. kyushu-u.ac.jp TOSHIHIKO KANEZAKI, Postdoctoral Researcher, is with the Research Center for Hydrogen Industrial Use and Storage (HYDROGENIUS), National Institute of Advanced Industrial Science and Technology (AIST). YOJI MINE, Assistant Professor, and SABURO MATSUOKA, Professor, The Research Center for Hydrogen Industrial Use and Storage (HYDROGENIUS), National Institute of Advanced Industrial Science and Technology (AIST), Fukuoka, 819-0395, Japan, are with the Department of Mechanical Engineering Science, Graduate School of Engineering, Kyushu University, Fukuoka, 819-0395, Japan.

Manuscript submitted November 25, 2007.

Article published online April 1, 2008 strength by hydrogen, although no direct observation of lattice decohesion has been made.

The hydrogen-enhanced localized plasticity (HELP) model is based on the in-situ observation by transmission electron microscopy (TEM) $)^{[3-5]}$ of the dislocation movement enhanced by hydrogen. However, no direct observation of the fracture phenomenon caused by the HELP model has been made.

Most research on HE over the past 40 years ${ }^{[1-31]}$ has paid insufficient attention to two points that are crucially important in the elucidation of the true mechanism. One is that, in most studies, the hydrogen content of specimens was not identified. Only about ten references (for example, References 6, 7, 15, and 20) of the more than several hundred articles recently surveyed by the authors include data on the measurement of hydrogen content.

The other point is that studies that have revealed the influence of hydrogen on fatigue crack growth behavior, based on microscopic observations, are very rare; most studies have examined the influence of hydrogen on tensile properties. ${ }^{[1-20]}$

The present authors have investigated microscopically the effect of hydrogen on fatigue crack growth behavior, including the measurement of the exact hydrogen content, in various materials such as low-carbon, $\mathrm{Cr}-\mathrm{Mo}$, and stainless steels. For example, particularly important phenomena found by the authors' fatigue studies (Murakami et al. ${ }^{[32,33]}$ Uyama et al.. ${ }^{[34,35]}$ Kanezaki et al., ${ }^{[36]}$ and Tanaka et al. ${ }^{[37]}$ ) are the localization of fatigue slip bands, strain-induced martensitic transformation in types 304, 316, and even $316 \mathrm{~L}$, and also strong frequency effects on fatigue crack growth rates. These unique phenomena observed in fatigue experiments are presumed to have an important correlation with the basic process of the HELP model proposed by Birnbaum et al. ${ }^{[3-5]}$ 
In this study, the load frequency effect of hydrogen on fatigue crack growth rates has been revealed to be a coupled phenomenon between fatigue crack growth rates and hydrogen diffusion rates to fatigue crack tips, i.e., the competition between the crack growth rate and the hydrogen diffusion rate..$^{[22,34,37]}$ This viewpoint is especially important in elucidating the mechanism of HE. If both the crack growth rate and the load frequency are low, there is sufficient time for the hydrogen to move through dislocations, or straininduced martensite, to the crack tip, where there is a high hydrostatic tension field, which enhances slip at the crack tip. However, if the crack growth rate becomes high, under a high stress intensity factor range, $\Delta K$, there is insufficient time for the hydrogen to move to the crack tip, even at low load frequencies. This is because the crack tip does not remain in one place: it advances so quickly that the hydrogen cannot reach the moving crack tip.

Thus, from the viewpoint of the hydrogen movement and the concentration of hydrogen at fatigue crack tips, the following factors must be considered, with particular emphasis on HE studies:

(a) the hydrogen content of materials,

(b) the hydrogen diffusion rate,

(c) the cyclic load frequency, and

(d) the stress fields in the vicinity of crack tips (especially the value of $\Delta K$ ).

The present study elucidates the basic mechanism of the phenomenon of HE, from the four viewpoints identified here, by investigating the fatigue crack growth behavior of type 304 and $316 \mathrm{~L}$ stainless steels.

\section{A. Hydrogen Content in Materials}

The level of hydrogen content in ordinary heat-treated bcc metals is on the order of $0.01 \mathrm{wppm}^{[34,35]}$ and, in ordinary solution-treated austenitic stainless steels, ${ }^{[36]}$ it is on the order of 2 to approximately $3 \mathrm{wppm}$. This level of hydrogen content in austenitic stainless steels has been considered to be normal, and is the amount of nondiffusible (irreversible) hydrogen. Because this hydrogen is nondiffusible (irreversible), it has not previously been considered as a possible influence on HE properties. On the other hand, it is well known that the hydrogen levels of 2 to approximately $3 \mathrm{wppm}$ drastically degrade the fatigue strength properties of bcc metals. ${ }^{[33]}$ It is also well known that, in air, the hydrogen content decreases with time, even if several weight ppm of hydrogen is charged into a material. This is due to the high hydrogen diffusion rate in bcc metals.

Typical examples of measurements of the decrease in the hydrogen content of bcc metals with time are shown in References 34, 35, and 37. On the other hand, since the hydrogen diffusion rates in austenitic stainless steels are on the order of $10^{-4}$ those of bcc metals, ${ }^{[36,38,39]}$ both diffusible and nondiffusible hydrogen remain in a material for a long time. However, here we have a mystery: why does a hydrogen level of 2 to approximately $3 \mathrm{wppm}$ in solution-treated austenitic stainless steels not influence HE? In austenitic stainless steels, is it correct to regard nondiffusible (irreversible) hydrogen at a level of 2 to approximately $3 \mathrm{wppm}$ as not influencing HE? The present study gives the solution of this mystery.

\section{B. Hydrogen Diffusion Rate}

Table I shows hydrogen diffusion rates for some bcc metals: type 405 stainless steel and austenitic stainless steels (types 304, 316, and 316L), which were measured during the authors' previous studies. The hydrogen diffusion rate of type 405 stainless steel is on the order of $10^{-12}\left(\mathrm{~m}^{2} / \mathrm{s}\right)$ and the diffusion rates of fcc metals are on the order of $10^{-15}$ to approximately $10^{-16}\left(\mathrm{~m}^{2} / \mathrm{s}\right)$ (Table $\left.\mathrm{I}(\mathrm{a})\right)$.

Table I(b) shows that hydrogen diffusion rates increase with prestraining. This implies that the hydrogen diffuses and concentrates at crack tips because strain concentrations are much higher there than elsewhere. This hydrogen concentration enhances slip in grains at crack tips by a coupled mechanism between hydrogen diffusion and deformation.

Table I. Hydrogen Diffusion Coefficients in Specimens: (a) Hydrogen Diffusion Coefficient at 323 K in Solution-Treated Austenitic Stainless Steels and an Annealed Ferritic Stainless Steel (Type 405) and (b) Hydrogen Diffusion Coefficient at 353 K in Prestrained Specimens of Types 304 and 316L and a Solution-Treated Specimen of Type 304

(a)

Type Hydrogen diffusion coefficient at $323 \mathrm{~K}\left(\mathrm{~m}^{2} / \mathrm{s}\right)$

304

316

$316 \mathrm{~L}$

405

$1.1 \times 10^{-15}$
$2.0 \times 10^{-15}$
$2.4 \times 10^{-16}$
$2.8 \times 10^{-12}$

(b) Hydrogen diffusion coefficient at $353 \mathrm{~K}\left(\mathrm{~m}^{2} / \mathrm{s}\right)$

Solution-treated 304 ( $\alpha^{\prime}$ : to approximately 3 pct)

304 prestrained at $29{ }^{\circ} \mathrm{C}\left(\varepsilon_{p}=0.29, \alpha^{\prime}: 1\right.$ to approximately $\left.3 \mathrm{pct}\right)$

304 prestrained at $-70{ }^{\circ} \mathrm{C}\left(\varepsilon_{p}=0.28, \alpha^{\prime}: 65\right.$ to approximately $\left.69 \mathrm{pct}\right)$

$316 \mathrm{~L}$ prestrained at $-70{ }^{\circ} \mathrm{C}\left(\varepsilon_{p}=0.30, \alpha^{\prime}: 26\right.$ to approximately $\left.28 \mathrm{pct}\right)$

$5.5 \times 10^{-15}$

$5.5 \times 10^{-15}$

$2.4 \times 10^{-13}$

$5.4 \times 10^{-14}$

$\varepsilon_{p}:$ plastic prestrain, and $a^{\prime}:$ martensite content. 


\section{Cyclic Load Frequency}

At low load frequency, there is sufficient time for hydrogen to move to a crack tip during the one crack advance during one stress cycle. If hydrogen does influence the localization of slip, i.e., the plastic deformation at a crack tip, the crack tip opening and closing behavior must also be strongly influenced. This is because the mechanism of crack tip opening displacement (CTOD) is based on the slip-off mechanism. ${ }^{[40-43]}$ As shown in Section III-D, the effect of hydrogen on the CTOD results in a change in the striation morphology. It will be shown that this change in striation shape can be attributed to hydrogen-induced increases in crack growth rates.

\section{Stress Field at a Crack Tip (Especially the Value of Stress Intensity Factor Range $\Delta K$ )}

The stress field, namely, the value of the stress intensity factor range $\Delta K$ at a crack tip, naturally influences the hydrogen concentration at the crack tip. A typical example, for a Cr-Mo steel (JIS SCM435), was given in Reference 37.

In this article, it will be shown that a similar phenomenon does occurs in austenitic stainless steels, even though these steels have the fcc lattice structure, and the degree of frequency influence is very different from that of bcc metals, such as Cr-Mo steels.

\section{MATERIALS AND EXPERIMENTAL METHODS}

\section{A. Materials and Specimens}

The materials used in this study are round bars of two kinds of austenitic stainless steels (types 304 and
316L stainless steel). Table II shows the chemical compositions and the Vickers hardnesses (load: $9.8 \mathrm{~N}$ ) of these materials. The round bars of types 304 and $316 \mathrm{~L}$ were solution heat treated. The solution heat treatment was performed by water quenching, after keeping the temperature at $1050{ }^{\circ} \mathrm{C}$ for 2 minutes for type 304 and 10 minutes for type $316 \mathrm{~L}$. The nondiffusible hydrogen content of the solution-treated specimen is $2.2 \mathrm{wppm}$ for type 304 and 2.6 wppm for type $316 \mathrm{~L}$. The hydrogen content were measured by thermal desorption spectrometry (TDS) using a quadruple mass spectrometer. The measurement accuracy of the TDS is $0.01 \mathrm{wppm}$. However, nondiffusible hydrogen has not previously been suspected as the cause of HE. Figures 1(a) and (b) show the fatigue specimen dimensions and the dimensions of the small hole that was introduced into the specimen surface. After polishing with \#2000 emery paper, the specimen surface was finished by buffing, using colloidal $\mathrm{SiO}_{2}$ $(0.04-\mu \mathrm{m})$ solution. A small artificial hole, $100 \mu \mathrm{m}$ in diameter and $100-\mu \mathrm{m}$ deep, was drilled into the specimen surface as a fatigue crack growth starter. In the hydrogen-charged specimens, the specimen surface was buffed after hydrogen charging, and the hole was then introduced immediately.

The amount of martensite at the specimen surface and at the fracture surfaces of the austenitic steel specimens was measured by the X-ray diffraction (XRD) method, using monochromatic $\mathrm{Cr} K_{\alpha}$ radiation. The martensite content was evaluated by the ratio of the integrated intensity of the $\{220\}$ austenite peaks and the $\{211\}$ martensite peaks. The amount of martensite before fatigue testing in the type 304 and 316L specimens was approximately 3 pct, at most. It should be noted that the amount of martensite measured by the XRD method also includes the amount of $\delta$-ferrite.

Table II. Chemical Composition (Weight Percent, *wppm) and Vickers Hardness $H V$

\begin{tabular}{lcccccccccc}
\hline & $\mathrm{C}$ & $\mathrm{Si}$ & $\mathrm{Mn}$ & $\mathrm{P}$ & $\mathrm{S}$ & $\mathrm{Ni}$ & $\mathrm{Cr}$ & $\mathrm{Mo}$ & $\mathrm{H}^{*}$ & $H V$ \\
\hline 304 & 0.06 & 0.36 & 1.09 & 0.030 & 0.023 & 8.19 & 18.66 & - & 2.2 & 176 \\
$316 \mathrm{~L}$ & 0.019 & 0.78 & 1.40 & 0.037 & 0.010 & 12.08 & 17.00 & 2.04 & 2.6 & 157 \\
\hline
\end{tabular}

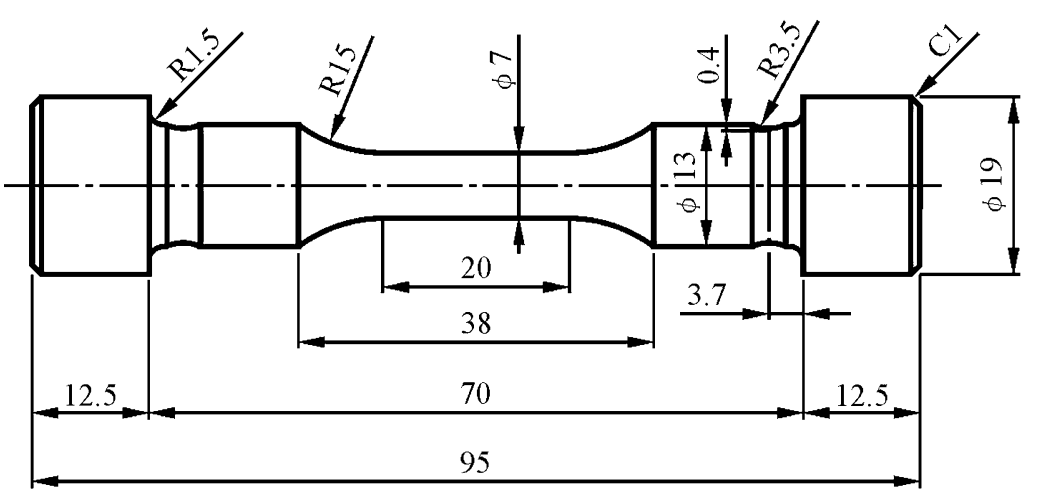

(a) Tension-compression specimen

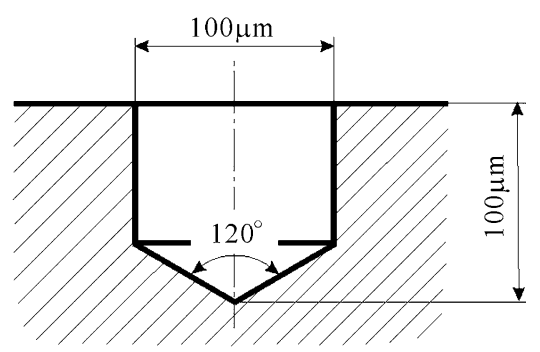

(b) Small artificial hole

Fig. 1-Dimensions of the fatigue test specimen and drilled hole. 


\section{B. Method of Hydrogen Charging}

Hydrogen was charged into specimens either by cathodic charging ${ }^{[36]}$ or by exposure to high-pressure hydrogen gas. The high-pressure hydrogen gas exposure was carried out in $63 \mathrm{MPa}$ hydrogen gas at $110^{\circ} \mathrm{C}$ for 91 hours. The high-pressure hydrogen gas was produced by the method developed by Mine et al., ${ }^{[4]}$ using the hydrogen absorption and desorption process of a metal hydride.

\section{Method of Fatigue Testing}

Fatigue tests of the hydrogen-charged and uncharged specimens were carried out at room temperature in laboratory air. The fatigue tests were conducted at a stress ratio $R=-1$ and at a testing frequency of $1.5 \mathrm{~Hz}$ by tension-compression cyclic loading (sine wave). Fatigue tests at very low frequency were carried out to investigate the effects of hydrogen and test frequency on fatigue crack growth. In the very-low-frequency fatigue tests, the fatigue tests were first carried out at $1.5 \mathrm{~Hz}$, until the fatigue crack length $2 a$ reached $200 \mu \mathrm{m}$, followed by testing at $0.0015 \mathrm{~Hz}(11 \mathrm{~min} /$ cycle $)$. The replica method was used for the measurements of crack length and for the observation of crack growth behavior. Following the fatigue tests, in order to measure the hydrogen content remaining in specimens, $0.8-\mathrm{mm}$-thick disks were immediately cut from each specimen, under water cooling. The hydrogen content of disks was then measured by TDS, using a quadruple mass spectrometer. The measurement accuracy of the TDS is $0.01 \mathrm{wppm}$. Measurements were carried out up to $800{ }^{\circ} \mathrm{C}$ at a heating rate of $0.5^{\circ} \mathrm{C} / \mathrm{s}$. It was confirmed that cutting disks from a specimen did not affect the hydrogen content of the disk sample. ${ }^{[36]}$

\section{RESULTS AND DISCUSSION}

\section{A. Hydrogen Entry into Austenitic Stainless Steels}

Figure 2 shows the hydrogen desorption spectra for an uncharged type $316 \mathrm{~L}$ specimen (curve A) and for a hydrogen-charged specimen (curve B). The height of the peak at around $300{ }^{\circ} \mathrm{C}$, which indicates diffusible hydrogen, shows an increase due to hydrogen charging. On the other hand, the height of the peak at around $400{ }^{\circ} \mathrm{C}$, which indicates nondiffusible hydrogen, shows that there is no significant difference between the hydrogen-charged and uncharged specimens. It should be noted that $2.6 \mathrm{wppm}$ nondiffusible hydrogen is contained, even in the uncharged type 316L. Although the data are not shown in the figure, the hydrogen desorption spectra for type 304 were similar to those for type 316L. The uncharged type 304 specimen contained 2.2-wppm nondiffusible hydrogen.

The hydrogen content distributions from the surface to below the surface were measured by the method developed by Kanezaki et al. ${ }^{[36]}$ Under cathodic charging, hydrogen diffused only into a very thin surface layer (100- to approximately $200-\mu \mathrm{m}$ deep) in the austenitic stainless steels. A very high hydrogen content

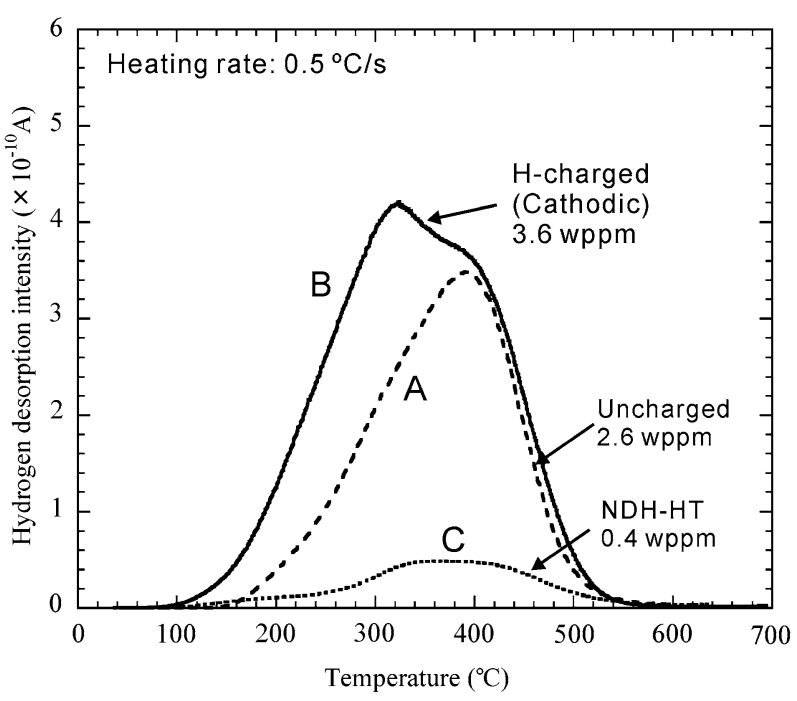

Fig. 2-Hydrogen thermal desorption spectrum of type 316L.

(10 to approximately $60 \mathrm{wppm}$ ) is contained within the thin (100- $\mu \mathrm{m}$ deep) surface layer. ${ }^{[36]}$

\section{B. Effects of Hydrogen and Test Frequency on Fatigue Crack Growth}

Figures 3(a) and (b) show the relationship between the crack length, $2 a$, and the number of cycles, $N$, for specimens of types 304 and $316 \mathrm{~L}$. The hydrogen content of the hydrogen-charged specimens, which was measured immediately after fatigue tests, is also included in the figure. The crack length is defined by adding the initial hole diameter. Figure 3(c) shows the relationship between the fatigue crack growth rate, $\mathrm{d} a / \mathrm{d} N$, and the stress intensity factor range, $\Delta K$, for type 316L. In type $316 \mathrm{~L}$ tested at a frequency of $1.5 \mathrm{~Hz}$, there was no pronounced difference between the hydrogen-charged and uncharged specimens. The fatigue crack growth rates of the hydrogen-charged type $316 \mathrm{~L}$, tested at the frequency $f=0.0015 \mathrm{~Hz}$, were 2 to 3 times higher than those of type $316 \mathrm{~L}$, tested at $f=1.5 \mathrm{~Hz}$. In particular, in the $\Delta K$ range from 8 to $10 \mathrm{MPa} \cdot \mathrm{m}^{1 / 2}$, the increase in the crack growth rate was remarkable. Surprisingly, the uncharged specimen also exhibited an obviously definite crack growth rate increase as the test frequency decreased from 1.5 to $0.0015 \mathrm{~Hz}$.

The crack growth rates of both the hydrogen-charged and uncharged specimens of type $316 \mathrm{~L}$, tested at a frequency of $1.5 \mathrm{~Hz}$, are expressed by

$$
\begin{aligned}
d a / d N= & 1.36 \times 10^{-11}(\Delta K)^{3.27} \\
& \text { for } 7 \mathrm{MPa} \cdot \mathrm{m}^{1 / 2}<\Delta K<25 \mathrm{MPa} \cdot \mathrm{m}^{1 / 2}
\end{aligned}
$$

On the other hand, the crack growth rates of the hydrogen-charged and uncharged specimens of type $316 \mathrm{~L}$, tested at a frequency of $0.0015 \mathrm{~Hz}$, are expressed by

$$
\begin{aligned}
d a / d N= & 1.78 \times 10^{-11}(\Delta K)^{3.52} \\
& \text { for } 7 \mathrm{MPa} \cdot \mathrm{m}^{1 / 2}<\Delta K<9 \mathrm{MPa} \cdot \mathrm{m}^{1 / 2}
\end{aligned}
$$




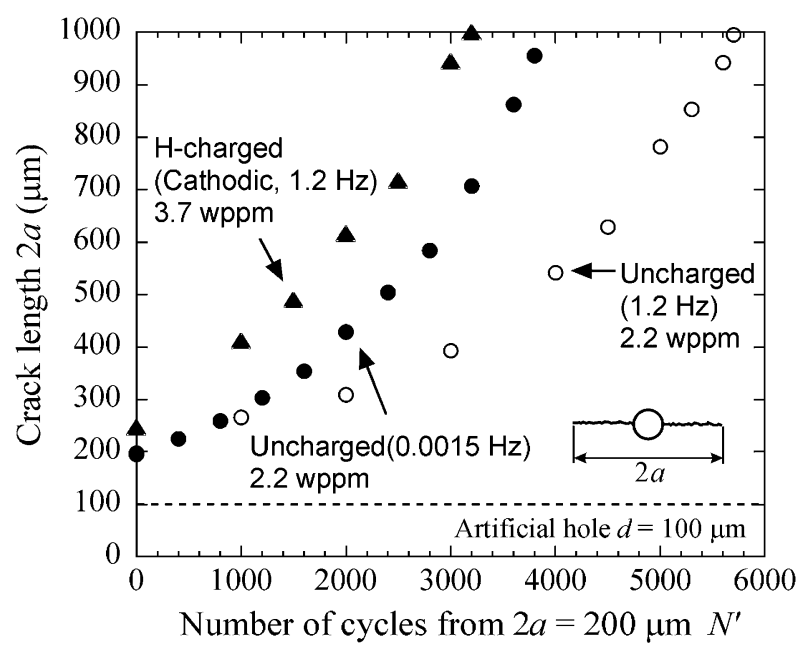

(a)

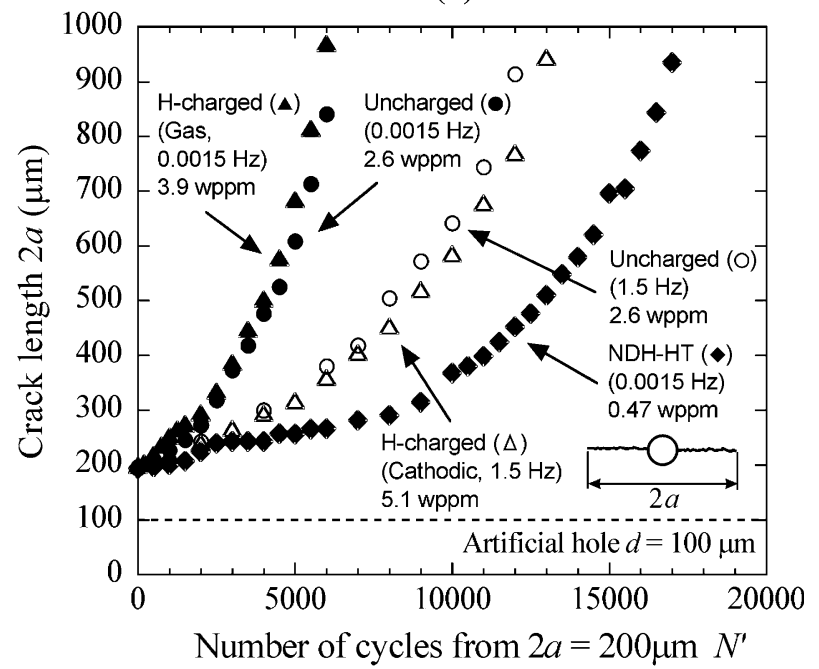

(b)

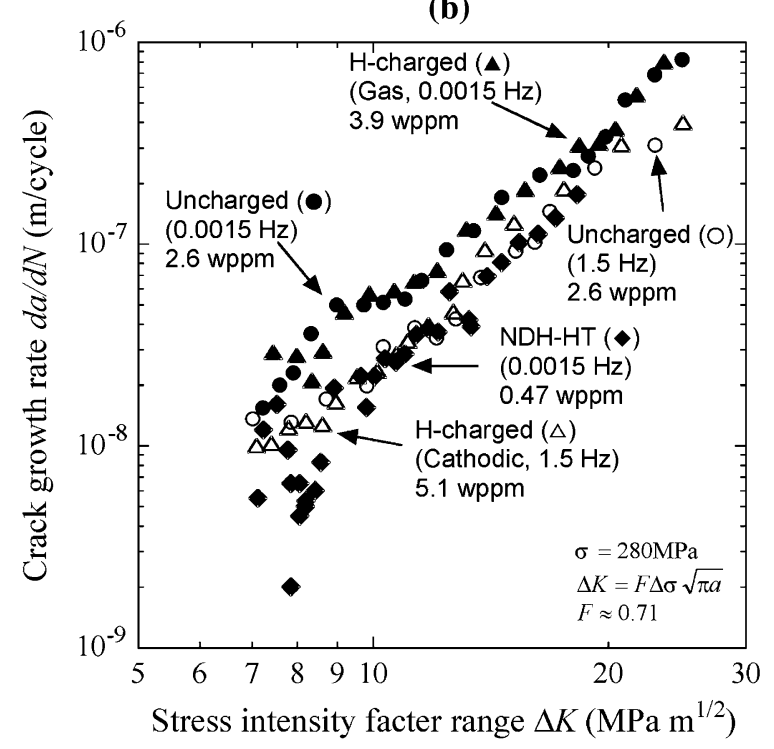

(c)

Fig. 3-Influence of hydrogen and test frequency on crack growth from $2 a=200 \mu \mathrm{m}$, of $(a)$ type $304(\sigma=280 \mathrm{MPa}),(b)$ type $316 \mathrm{~L}$ $(\sigma=280 \mathrm{MPa})$, and $(c)$ effect of hydrogen and test frequency on crack growth rate of type $316 \mathrm{~L}$. and

$$
\begin{aligned}
d a / d N= & 6.26 \times 10^{-11}(\Delta K)^{2.91} \\
& \text { for } 9 \mathrm{MPa} \cdot \mathrm{m}^{1 / 2} \leq \Delta K<25 \mathrm{MPa} \cdot \mathrm{m}^{1 / 2}
\end{aligned}
$$

In the range of $\Delta K<9 \mathrm{MPa} \cdot \mathrm{m}^{1 / 2}$, the crack growth rate is slow and it is presumed that there is sufficient time for hydrogen to concentrate in the vicinity of crack tip during one cycle at a frequency of $0.0015 \mathrm{~Hz}$. Hence, the values of both exponent and constant in Eq. [2] are larger than those in Eq. [1]. On the other hand, in the range of $\Delta K>9 \mathrm{MPa} \cdot \mathrm{m}^{1 / 2}$, the fatigue crack growth rates of the hydrogen-charged and uncharged specimens, tested at a frequency of $0.0015 \mathrm{~Hz}$, gradually increased and approached to those tested at a frequency of $1.5 \mathrm{~Hz}$, though the value of constant in Eq. [3] is larger than that in Eq. [1] and the value of exponent in Eq. [3] is smaller than that in Eq. [1].

In both type 304 and type $316 \mathrm{~L}$, the uncharged specimen exhibited a definite frequency effect. As the test frequency decreased from 1.2 to $0.0015 \mathrm{~Hz}$, fatigue crack growth rates increased (Figure 3(a)).

Figure 4 shows the micrographs of the fatigue cracks taken by the replica method for the type 304 specimens. For type 304 tested at a frequency of $1.2 \mathrm{~Hz}$, the fatigue crack in the hydrogen-charged specimen grew straighter than did that in the uncharged specimen. Slip bands in the hydrogen-charged specimen were more localized, in the vicinity of the crack tips, compared to those in the uncharged specimen, which was tested at the same stress level, as shown in Figures 4(a) and (c). Even for the uncharged type 304 specimen, localization of the slip bands in the crack tip vicinity was observed in the low-frequency test $(f=0.0015 \mathrm{~Hz})$, although the extent of the slip localization was less pronounced than for the hydrogencharged type 304 specimen $(f=1.2 \mathrm{~Hz}$, Figure 4(c)). Although the fatigue test for the hydrogen-charged type 304 at a frequency of $0.0015 \mathrm{~Hz}$ was not carried out, the result can be easily predicted from the data of the type $316 \mathrm{~L}$ shown in Figure 3. The slip bands in the hydrogen-charged type 304 tested at a frequency of $0.0015 \mathrm{~Hz}$ will be at least similar to that tested at a frequency of $1.2 \mathrm{~Hz}$, or will be more localized than that tested at a frequency of $1.2 \mathrm{~Hz}$, because, in the fatigue test at a frequency of $0.0015 \mathrm{~Hz}$, there is sufficient time for the hydrogen to concentrate in the vicinity of the crack tip during one cycle.

Figure 5 shows the micrographs of fatigue cracks for type 316L. Slip bands in the hydrogen-charged specimen of type $316 \mathrm{~L}$ were more localized compared to those in the uncharged specimen at the same test frequency. However, the hydrogen effect on slip band formation was less pronounced in type 316L than in type 304 (compare Figures 5(a) and (b) and also Figures 5(c) and (d)). The slip band density in the uncharged specimen at a frequency of $0.0015 \mathrm{~Hz}$ is higher than that at $1.5 \mathrm{~Hz}$ (compare Figures 5(a) and (c)). This is also the case for the hydrogen-charged specimens (compare Figures 5(b) and (d)). Therefore, the difference in slip band density between Figures 5(a) and (c) and also Figures 5(b) and (d) is presumed to be caused by the frequency effect on 


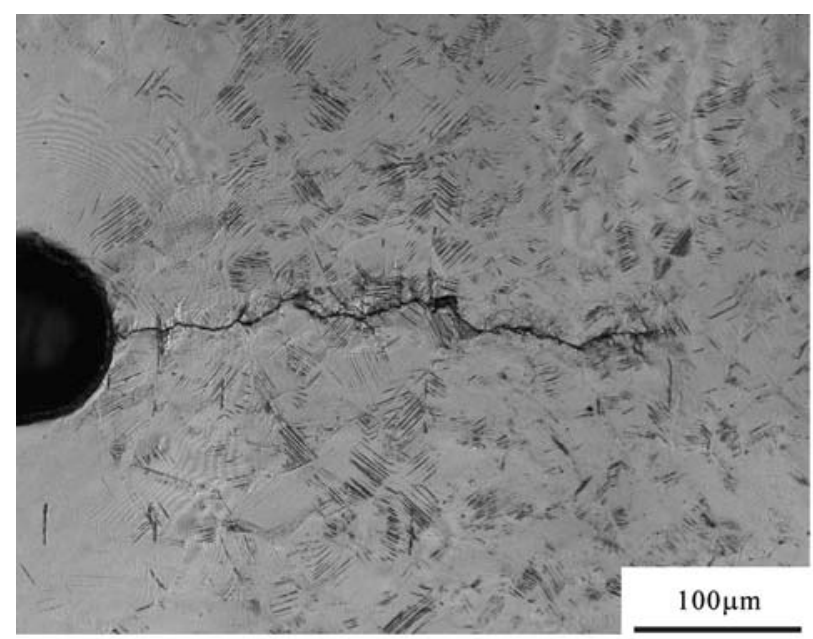

(a)

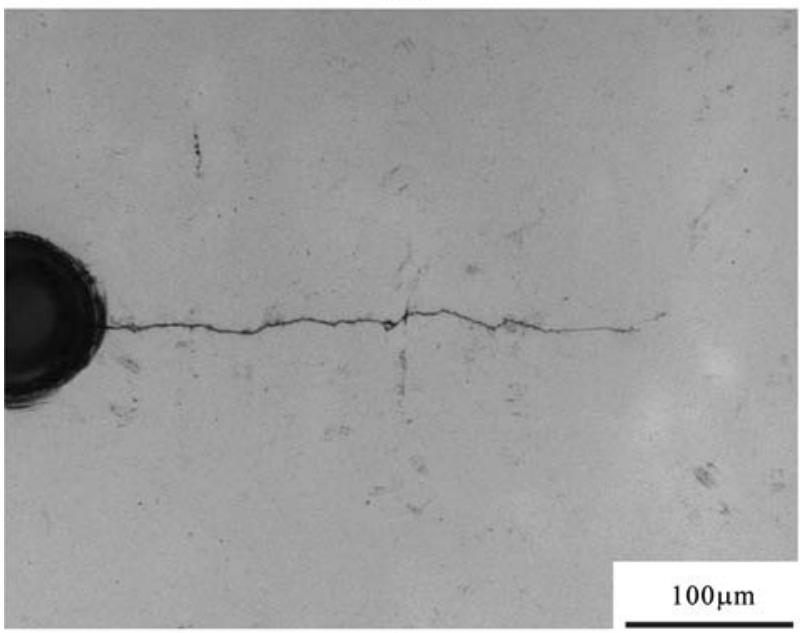

(c)

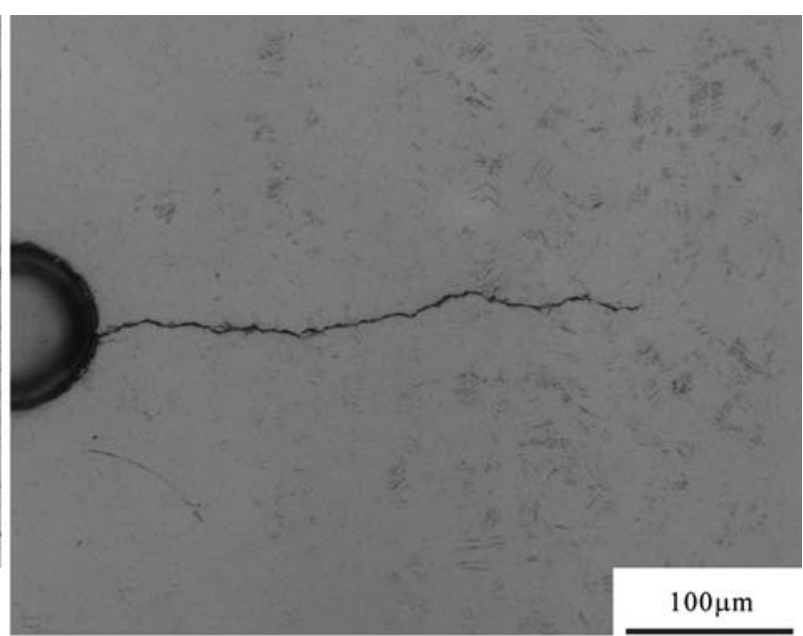

(b)

Fig. 4 -Difference in crack growth behavior between hydrogen-charged specimens and uncharged specimens of type $304(\sigma=280 \mathrm{MPa})$ : $(a)$ uncharged $(f=1.2 \mathrm{~Hz}, 2 a=782 \mu \mathrm{m}, 2.2 \mathrm{wppm}),(b)$ uncharged $(f=0.0015 \mathrm{~Hz}, 2 a=778 \mu \mathrm{m}, 2.2 \mathrm{wppm})$, and $(c) \mathrm{H}-\mathrm{charged}(f=1.2 \mathrm{~Hz}$, $2 a=801 \mu \mathrm{m}, 3.7 \mathrm{wppm})$.

the plastic deformation in type $316 \mathrm{~L}$ tested at the stress slightly higher than the static yield stress.

The authors' previous research work ${ }^{[36]}$ has indicated that strain-induced martensitic transformation at the crack tip could be considered to be one of the main causes of the crack growth rate increase due to hydrogen. Martensitic transformation must be considered as a crucial factor in the enhancement of hydrogen-induced fatigue crack growth rate increases. In this regard, the authors measured the volume fraction of martensite on the fracture surfaces of type 304 and $316 \mathrm{~L}$ specimens tested at a frequency of $0.0015 \mathrm{~Hz}$. Figure 6 shows the volume fractions of martensite for the fatigue fracture surface. The volume fraction of martensite was determined by the microscopic XRD technique. The collimator size of the X-ray beam was $0.5 \mathrm{~mm}$. Ambient temperatures during fatigue tests are included in Figure 6. This is because the amount of the martensitic transformation depends strongly on temperature. ${ }^{[45]}$ Strain-induced martensitic transformation occurred on fracture surfaces at both test frequencies, $f \sim 1.5 \mathrm{~Hz}$ and
$0.0015 \mathrm{~Hz}$. It should be noted that even in type $316 \mathrm{~L}$, which had previously been thought extremely difficult to transform to martensite at ambient temperature, martensitic transformation took place at fatigue crack tips. It should be also noted that martensitic transformation was detected only at the fatigue fracture surface and not at other places, such as the specimen surface, even in type 304.

The authors have reported that hydrogen decreased the area fraction of fatigue striations on the fatigue fracture surface in type 304 , and also that the ratio of the striation height, $H$, to striation spacing $s, H / s$, was reduced for a hydrogen-charged specimen. ${ }^{[36]}$ Taking these facts into consideration, striations observed on the fracture surfaces of types $316 \mathrm{~L}$ and 304 tested at the low frequency were, therefore, investigated. Figure 7 shows the topography of the striations observed in the hydrogen-charged and uncharged type 304 specimens tested under the same conditions. These topographies were obtained by constructing the threedimensional shape of striations by analysis of a pair of 


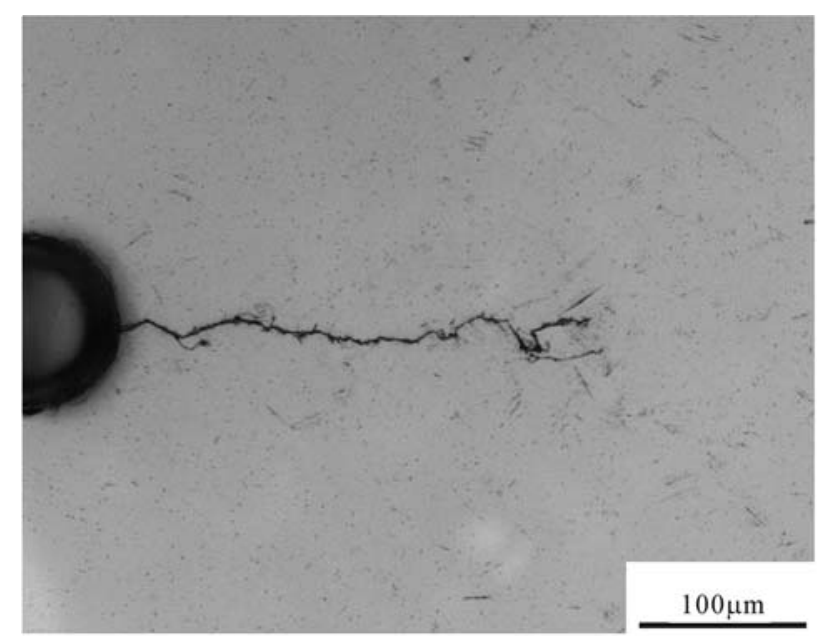

(a)

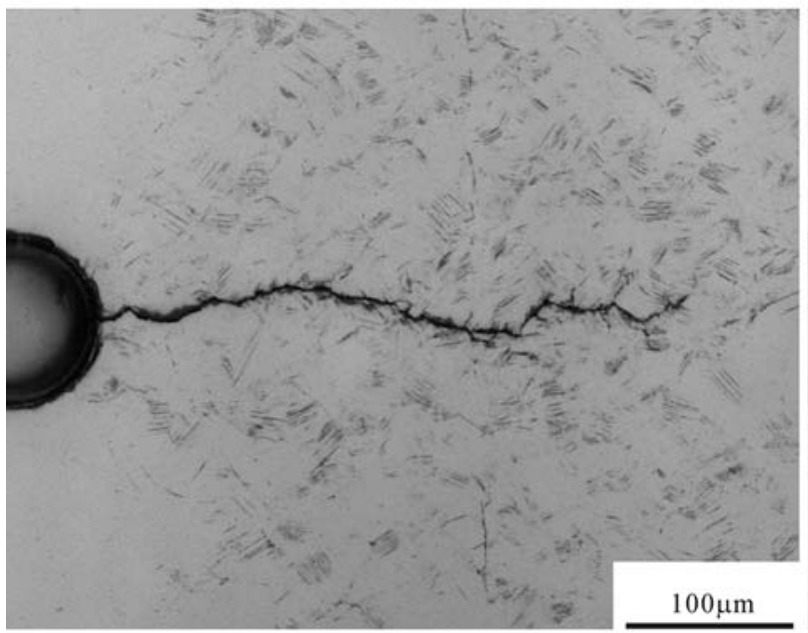

(c)

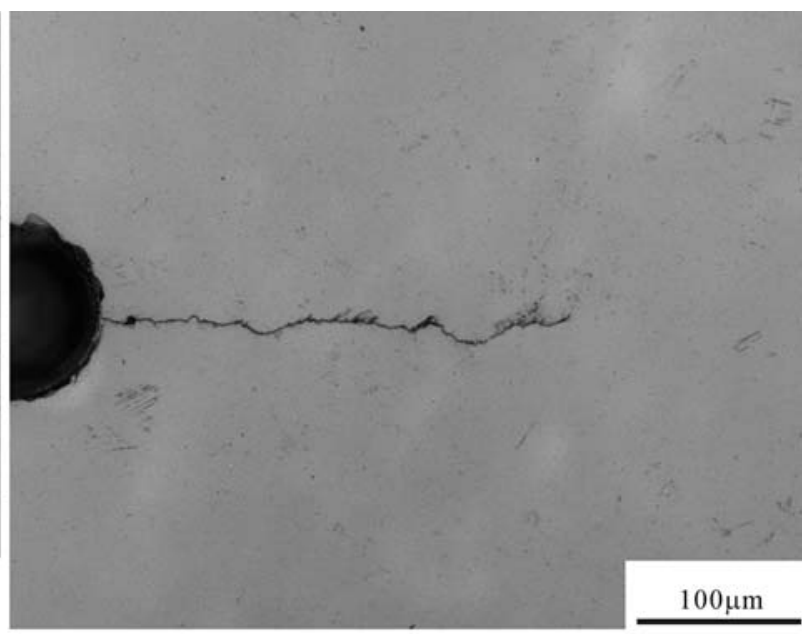

(b)

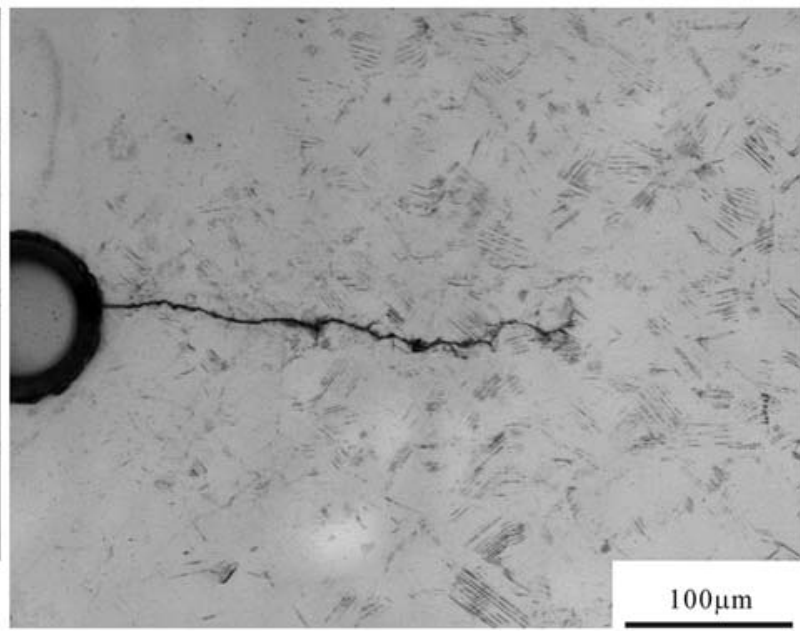

(d)

Fig. 5-Difference in crack growth behavior between hydrogen-charged specimens and uncharged specimens of type 316L $(\sigma=280 \mathrm{MPa})$ : (a) uncharged $(f=1.5 \mathrm{~Hz}, 2 a=743 \mu \mathrm{m}, 2.6 \mathrm{wppm}),(b)$ H-charged $(f=1.5 \mathrm{~Hz}, 2 a=678 \mu \mathrm{m}, 5.1$ wppm$),(c)$ uncharged $(f=0.0015 \mathrm{~Hz}$, $2 a=841 \mu \mathrm{m}, 2.6 \mathrm{wppm})$, and $(d)$ H-charged $(f=0.0015 \mathrm{~Hz}, 2 a=684 \mu \mathrm{m}, 3.9 \mathrm{wppm})$.

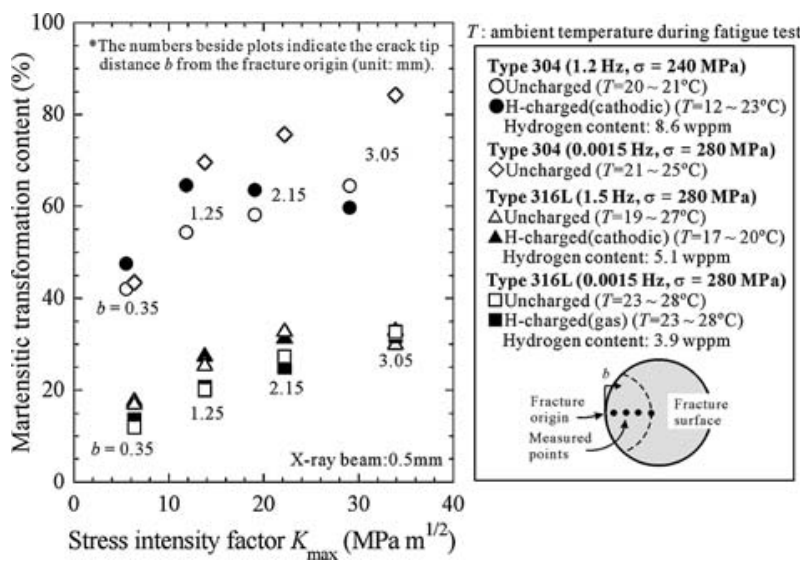

Fig. 6-Amount of martensitic transformation on fatigue fracture surface.

stereographic scanning electron microscopy (SEM) images. In the uncharged specimen, each striation was regularly formed and roughly triangular in shape. In the hydrogen-charged specimen, on the other hand, striations were irregularly shaped, and the striation height was lower compared to that of the uncharged specimen. Figure 8 shows histograms of the striation height to the spacing $H / s$ obtained at the stress ratio, $R=-1$. In previous work, Furukawa and Murakami et al. ${ }^{[46]}$ obtained the topography of striations by cutting the fatigue fracture surfaces of type 304 specimens with a microtome. They found a good correlation between the ratio $H / s$ and the $R$ ratio. Figure 9 shows the $H / s$ data for type 304 in the present study, together with the data of Furukawa and Murakami et al. The figure indicates that the $H / s$ data obtained from the stereographic SEM images in this study, for the uncharged specimen tested at $f=1.5 \mathrm{~Hz}$, had a good correlation with the data of Furukawa and Murakami et al. It can be seen from Figure 8(a) that the value of $H / s$ at the peak of the histogram for the uncharged specimen tested at $f=0.0015 \mathrm{~Hz}$ (Figure 8(a-2)), as well as that of the hydrogen-charged specimen (Figure $8(\mathrm{a}-3), f=1.5 \mathrm{~Hz}$, $6.7 \mathrm{wppm})$, were shifted to lower values compared to 


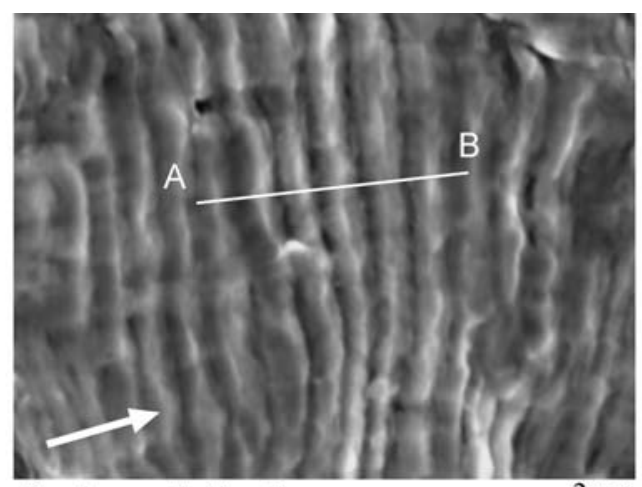

Crack growth direction

$2 \mu \mathrm{m}$

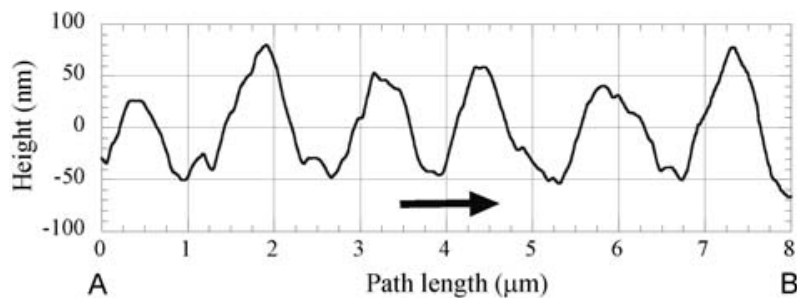

(a)

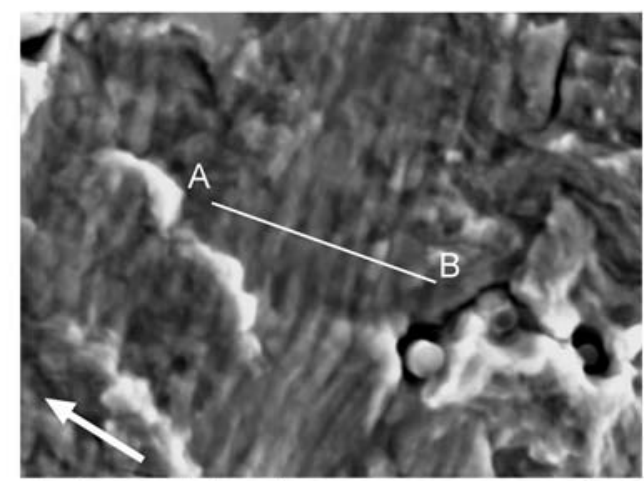

Crack growth direction

$2 \mu \mathrm{m}$

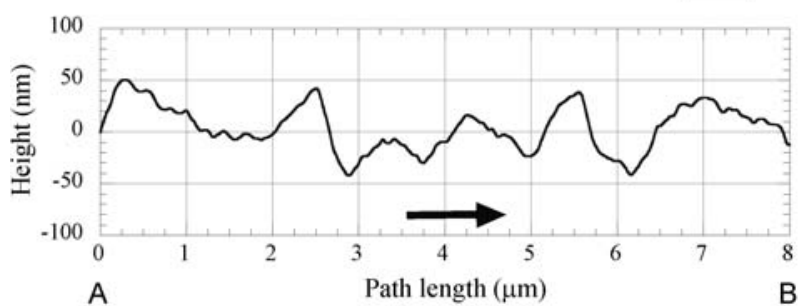

(b)

Fig. 7-Difference in striation morphology between a hydrogencharged specimen and an uncharged specimen of type 304: $(a)$ uncharged $(\sigma=260 \mathrm{MPa}, f=1.5 \mathrm{~Hz}, 2.2 \mathrm{wppm})$ and $(b) \mathrm{H}$-charged $(\sigma=260 \mathrm{MPa}, f=1.5 \mathrm{~Hz}, 6.7 \mathrm{wppm})$. The arrows in the figures indicate the crack growth direction.

that of the uncharged specimen tested at $f=1.5 \mathrm{~Hz}$. It should be noted that, even in type $316 \mathrm{~L}$, as seen from Figures 8(b-1) through (b-4), the coupled effect of hydrogen and test frequency is similar to that in type 304.

Considering that the features of striation shape for the uncharged specimen, tested at the frequency of $0.0015 \mathrm{~Hz}$ (Figure 8(a-2)), are very similar to those for the hydrogen-charged specimen (Figure 7(b)), it follows that testing at the low frequency $(f=0.0015 \mathrm{~Hz})$ enhances the hydrogen effect, even in the uncharged specimens that contain nondiffusible hydrogen at a level of 2 to approximately 3 wppm.

\section{What Happens When Nondiffusible Hydrogen Is Removed by Special Heat Treatment?}

Even in the uncharged specimens, the fatigue crack growth rate is increased by decreasing the test frequency down to $0.0015 \mathrm{~Hz}$. The only suspected cause of this surprising phenomenon is the effect of nondiffusible hydrogen, of the level of 2 to approximately 3 wppm, which is unavoidably trapped in the material during the production process. The nondiffusible hydrogen unavoidably contained in solution-treated austenitic stainless steels is different from the diffusible (or reversible) hydrogen, which is charged into a material by a hydrogen gas environment, or by electrochemical methods. This nondiffusible hydrogen has not been suspected, in previous $\mathrm{HE}$ studies, as a possible cause of $\mathrm{HE}$.

However, if this nondiffusible hydrogen can cause $\mathrm{HE}$, it means that the HE of austenitic stainless steels can occur even in the absence of an external hydrogen environment.

In order to investigate the influence of so-called nondiffusible hydrogen on fatigue crack growth, a special heat treatment was applied. This treatment involves soaking type $316 \mathrm{~L}$ at $450{ }^{\circ} \mathrm{C}$ for 450 hours, and type 304 at $300^{\circ} \mathrm{C}$ for 600 hours, in a vacuum of $6.0 \times 10^{-3} \mathrm{~Pa}$. In practice, this heat treatment was carried out by enclosing specimens, or samples, in an evacuated silica glass tube. During the heat treatment process, the partial pressure of the hydrogen in the glass tube increases, and this prevents the removal of hydrogen in the specimen to below the equilibrium hydrogen content for the increased partial pressure. Therefore, in order to avoid unwanted increases in the hydrogen partial pressure, the specimen was removed from the glass tube after heat treatment for 150 hours, and the same vacuum heat treatment process was then repeated in 150-hour increments. Fatigue testing was carried out using specimens that were prepared using the special heat treatment. The specification for this special heat treatment was determined by considering the temperature and time needed to avoid sensitization, and also to ensure the hydrogen diffusion out of the specimens. This heat treatment is completely different from the so-called "baking," which is conventionally applied to remove hydrogen introduced by processes such as welding and plating. Nondiffusible hydrogen at the level of 2 to approximately 3 wppm cannot be removed by means of the so-called baking.

In this article, we call this special heat treatment the nondiffusible hydrogen desorption- heat treatment (NDH-HT). The effect of NDH-HT is clearly shown in Figure 1, in which the hydrogen content in a type $316 \mathrm{~L}$ subject to ordinary heat treatment is $2.6 \mathrm{wppm}$ and in the sample subjected to NDH-HT is $0.4 \mathrm{wppm}$. Thus, the NDH-HT removes the hydrogen, which is strongly trapped at the center (O-site) of an octahedron 

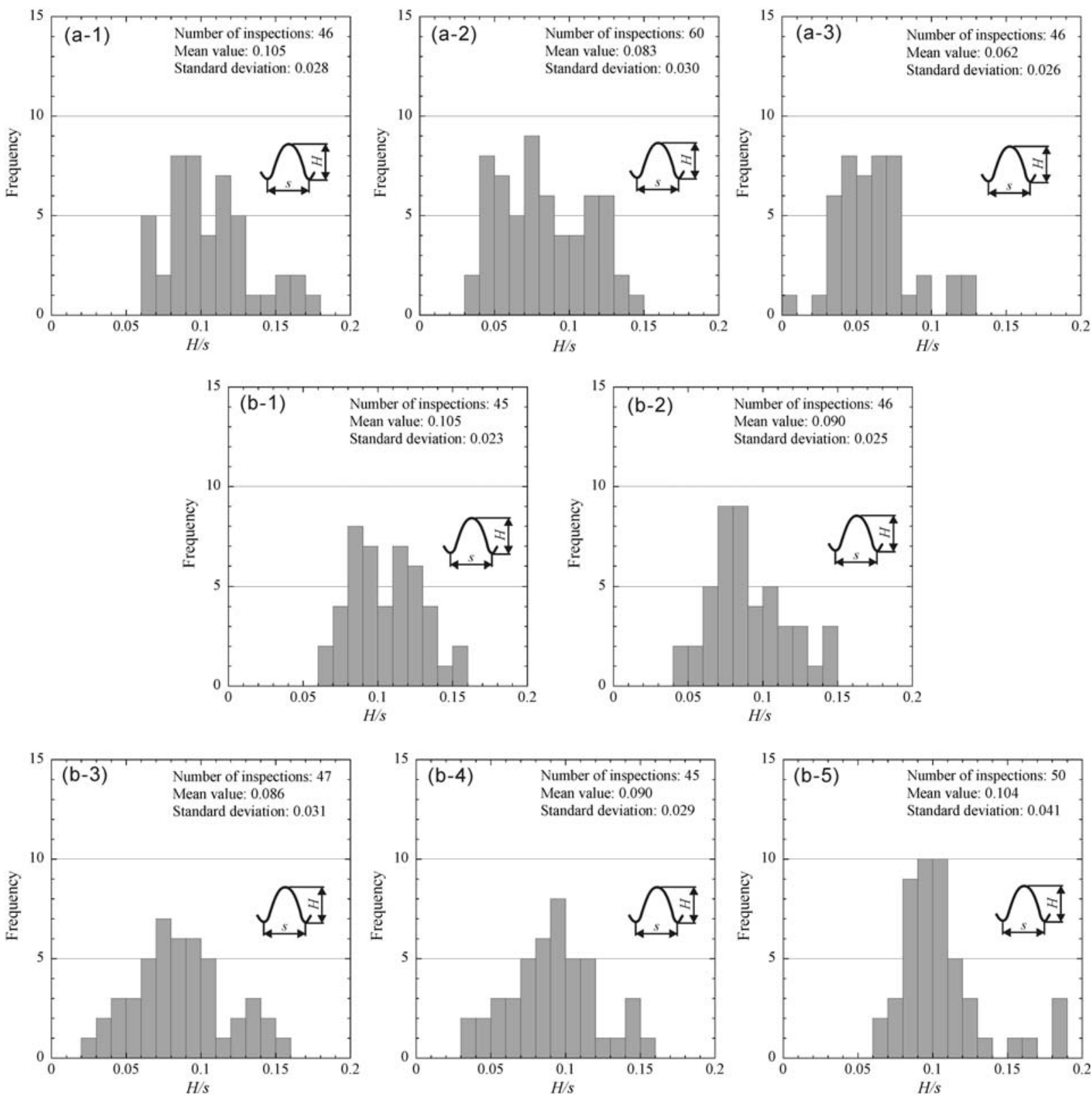

Fig. 8- Histograms of ratio of striation height $H$ to spacing $s, H / s:(a-1)$ uncharged type $304(\sigma=260 \mathrm{MPa}, f=1.5 \mathrm{~Hz}, 2.2 \mathrm{wppm}),(a-2)$ uncharged type $304(\sigma=280 \mathrm{MPa}, f=0.0015 \mathrm{~Hz}, 2.2 \mathrm{wppm}),(a-3) \mathrm{H}$-charged type $304(\sigma=260 \mathrm{MPa}, f=1.5 \mathrm{~Hz}, 6.7 \mathrm{wppm}),(b-1)$ uncharged type $316 \mathrm{~L}(\sigma=280 \mathrm{MPa}, f=1.5 \mathrm{~Hz}, 2.6 \mathrm{wppm}),(b-2) \mathrm{H}$-charged type $316 \mathrm{~L}(\sigma=280 \mathrm{MPa}, f=1.5 \mathrm{~Hz}, 5.1 \mathrm{wppm}),(b-3)$ uncharged type $316 \mathrm{~L}(\sigma=280 \mathrm{MPa}, f=0.0015 \mathrm{~Hz}, 2.6 \mathrm{wppm}),(b-4) \mathrm{H}$-charged type $316 \mathrm{~L}(\sigma=280 \mathrm{MPa}, f=0.0015 \mathrm{~Hz}, 3.9 \mathrm{wppm})$, and $(b-5)$ NDH-HT type 316L $(\sigma=280 \mathrm{MPa}, f=0.0015 \mathrm{~Hz}, 0.47 \mathrm{wppm})$.

of the fcc lattice, where the potential energy is much lower than that for hydrogen trapped in the quadratic lattice of a bcc material (T-site). ${ }^{[7]}$

The hydrogen content after NDH-HT was measured by TDS. In order to check that the material structure had not been sensitized by NDH-HT, the microstructure was etched; this confirmed that chromium carbides did not segregate at the grain boundaries. As further evidence of the avoidance of sensitizing, the Vickers hardness before and after NDH-HT was found to be largely unchanged (for type 304, $H V=176$ before and 172 after NDH-HT; for type $316 \mathrm{~L}, H V=157$ before and 163 after NDH-HT).
Figure 2 shows the hydrogen emission intensity profile (curve C), measured using TDS, for a specimen after NDH-HT. As can be seen in the figure, NDH-HT substantially decreases the peak value of the hydrogen emission intensity profile, and the total emission is also decreased from 2.6 to $0.4 \mathrm{wppm}$.

Figure 3 shows the fatigue crack growth behavior of the NDH-HT specimens. Fatigue tests were carried out at a frequency of $1.5 \mathrm{~Hz}$, until a crack had grown to $200 \mu \mathrm{m}$ in length, including the hole diameter $(100 \mu \mathrm{m})$, and the test frequency was then changed to $0.0015 \mathrm{~Hz}$. Surprisingly, the fatigue crack growth rate of an NDH-HT specimen was substantially decreased 


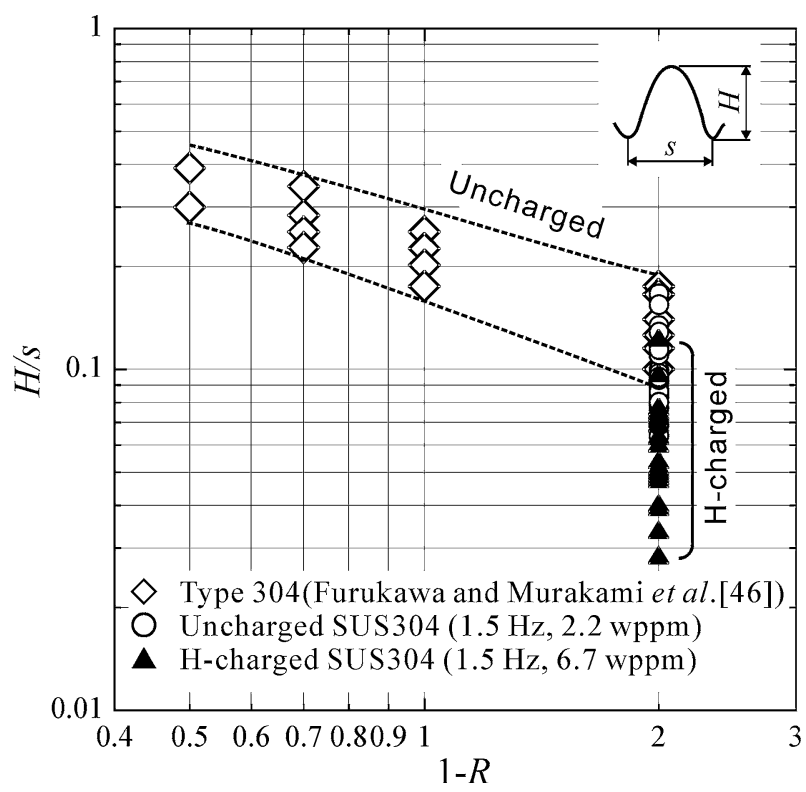

Fig. 9-Relationship between ratio of striation height $H$ to spacing $s, H / s$, and stress ratio $(1-R)$.

in comparison to a hydrogen-charged specimen and even in comparison to an uncharged specimen. Further evidence of the effect of NDH-HT can be seen in Figure $8(\mathrm{~b}-5)$, in which the striation height-spacing ratios $(H / s)$ are shifted to higher values. These facts are definite proof that even the nondiffusible hydrogen contained in ordinary solution-treated austenitic stainless steels influences fatigue crack growth rates. From the results of this experiment, we can identify two reasons for the increase in fatigue crack rates, at the very low test frequency of $0.0015 \mathrm{~Hz}$, in solutiontreated uncharged specimens, which naturally contain hydrogen at the level of 2 to approximately $3 \mathrm{wppm}$. These reasons are as follows.

(a) At a very low test frequency, on the order of $0.0015 \mathrm{~Hz}$, there is sufficient time for hydrogen to be transported to fatigue crack tips through lattice defects such as edge dislocations. In this case, it is presumed that the probability of the movement of the hydrogen out of O-sites is increased by the fluctuation of the potential energy, due to lattice deformation under very low stress frequencies.

(b) As austenite at fatigue crack tips partially transforms to strain-induced martensites, the binding energy between hydrogen and a trapping site is decreased, and, at the same time, the locally transformed martensites at the fatigue crack tip enhances the diffusion and concentration of hydrogen trapped in austenites to fatigue cracks. ${ }^{[36,48]}$

For example, at $0.0015 \mathrm{~Hz}$, with $\Delta K=10 \mathrm{MPa} \cdot \mathrm{m}^{1 / 2}$, for which the plastic zone size under plane strain is approximately $20 \mu \mathrm{m}$, based on a simple application of the Dugdale model, during one fatigue cycle (11 minutes), hydrogen can move approximately $0.4 \mu \mathrm{m}$ in plastically deformed austenites having a slightly higher diffusion rate than that for an undeformed structure
(Table I), whereas it can move approximately $3.5 \mu \mathrm{m}$ through transformed martensites.*

*We estimated hydrogen diffusion distance by $(D t)^{1 / 2}$. The term $D$ denotes the hydrogen diffusion coefficient shown in Table I and $t$ is the time during a fatigue cycle. The term $(D t)^{1 / 2}$ represents the position at which the hydrogen content is half of the surface value if hydrogen diffuses into a semi-infinite body from the surface only by concentration gradient. Approximately, $(D t)^{1 / 2}$ can be considered to be the hydrogen diffusion distance from the fatigue crack tip, if the fatigue test is carried out in a hydrogen gas. Although $(D t)^{1 / 2}$ does not strictly represent the hydrogen diffusion distance in the vicinity of the crack tip, we regarded that the relative difference in the hydrogen diffusion speed between martensite and austenite can be compared with the value of $(D t)^{1 / 2}$.

Thus, it is vitally important to take the effect of loading frequency into consideration for the prediction of fatigue lives and the safety of infrastructures and components, which, in actual service, are used in hydrogen environments. Current fatigue data obtained by conventional accelerated tests should therefore not be used for design to ensure the long term safety of hydrogen energy systems. Therefore, fatigue test methods must be reviewed from the viewpoints both of test frequency and of hydrogen content.

\section{Hydrogen-Induced Striation Formation Mechanism}

Based on the data for the striation shape, which involves information on the crack growth mechanism, we will discuss the mechanisms of crack tip opening, crack growth, and decrease in $H / s$ induced by hydrogen. We will also discuss the mechanisms related not only to the mechanism of $\mathrm{HE}$ in fatigue but also to the basic mechanism of $\mathrm{HE}$ in static fracture.

The distributions of the maximum shear stress and the hydrostatic tensile stress, ahead of the crack tip, under plane strain, can be easily calculated by the elastic solution of the crack. In the case in which there is no hydrogen, slip from the crack tip occurs in the 75.8-deg direction, where the shear stress has its maximum under plane strain. The slip in the 75.8-deg direction causes both crack tip blunting and crack growth at the initial stage of loading. Under a given load level, crack tip blunting occurs as a crack grows and, finally, at the maximum load, the crack growth is saturated. This mechanism has been well known in previous studies on metal fatigue. ${ }^{[40-43]}$ On the other hand, for the case in which hydrogen is present, Sofronis et al. ${ }^{[49]}$ showed by the numerical analysis of the hydrogen diffusion near the crack tip that hydrogen diffuses to, and concentrates at, the region in which the hydrostatic tensile stress has its maximum. Tabata, Birmbaum et al. ${ }^{[3]}$ suggested, through TEM observation of the interaction between dislocations and hydrogen, that yield stress decreases as a function of hydrogen pressure. Considering their experimental result, it is therefore presumed that yield stress decreases at a region in which hydrogen concentrates. As a result, crack tip blunting and crack growth both occur during the entire load cycle. Specifically, even if crack tip blunting occurs at a given load level that is below the maximum load, further slip takes place 
at the growing crack tip at which hydrogen repeatedly concentrates. This further slip reduces crack tip blunting in the 75.8-deg direction; both crack tip blunting and crack growth occur in a coupled manner during the entire load cycle. Sofronis et al. proposed a new constitutive equation that includes a parameter for the decrease in yield stress due to the presence of hydrogen, ${ }^{[50,51]}$ and that also simulated the growth and coalescence of voids due to the presence of hydrogen in a material. ${ }^{[52]}$ Their simulation indicated that, if the hydrostatic stress is larger than the maximum shear stress, the growth of shallow voids is accelerated by the presence of hydrogen. As shown in Figure 10, the fatigue crack growth mechanism of ductile materials is based on striations formed by slip at a crack tip. This differs from the static fracture mechanism of bec metals. However, the diffusion and concentration behavior of hydrogen near a crack tip, or near a notch root, is

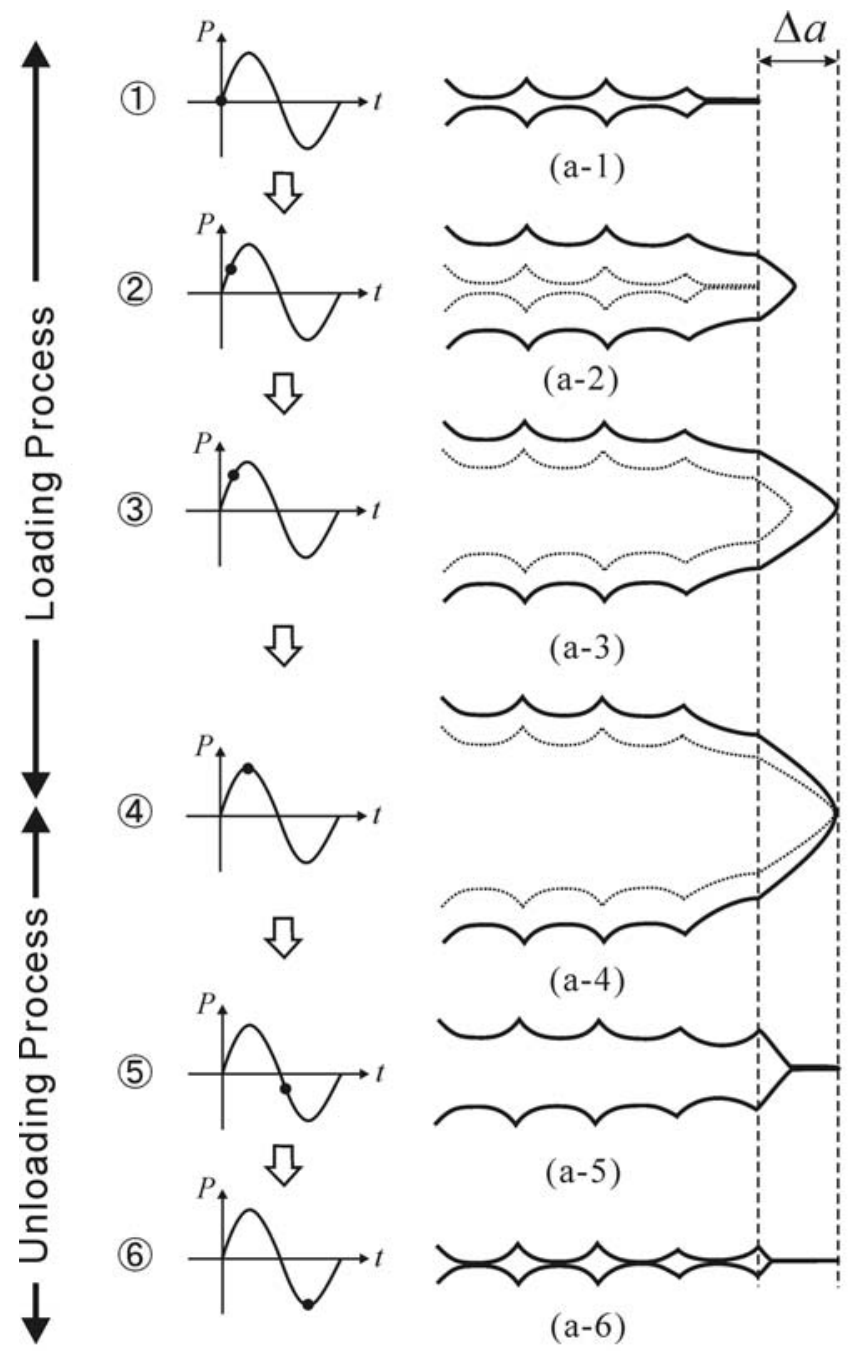

(a) No Hydrogen Effect [43]

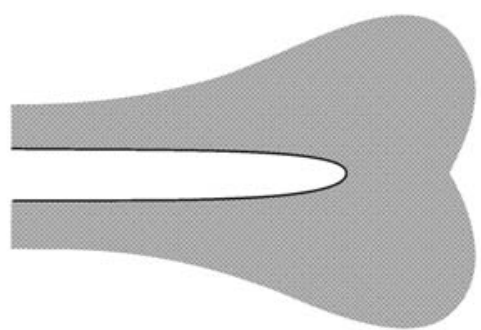

(c)

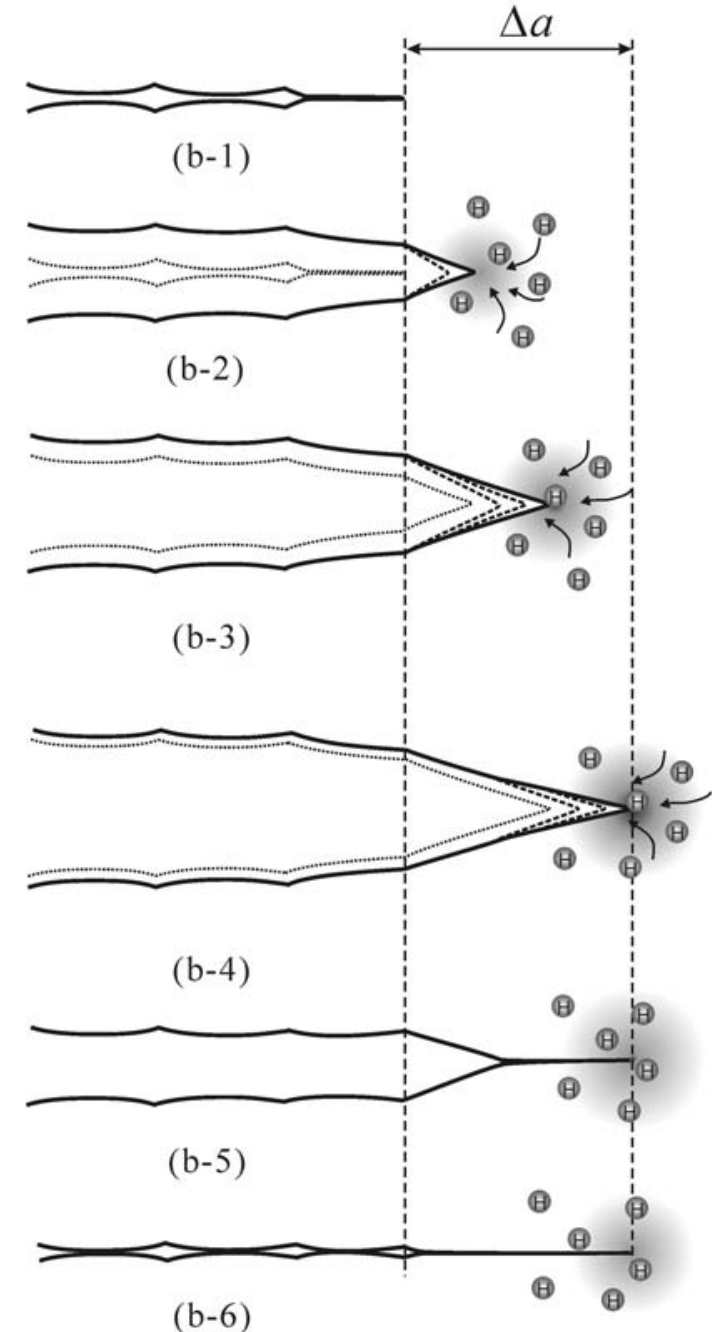

(b) Hydrogen Effect

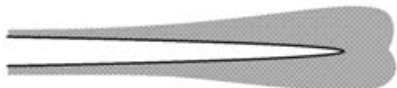

(d)

Fig. 10 - Crack tip opening and striation formation mechanism in fatigue: $(a)$ no hydrogen effect, $(b)$ hydrogen effect, $(c)$ schematic image of thick plastic zone wake produced at a crack under no hydrogen, and $(d)$ schematic image of shallow plastic zone wake produced at a crack under hydrogen effect. 
similar in both fcc and bcc metals. Furthermore, with decreasing fatigue test frequency, there is sufficient time for hydrogen to diffuse toward crack tips, and a large amount of hydrogen concentrates near crack tips. As a result, a crack continues to grow before the crack tip becomes fully blunt.

It is well known that there are three types of crack closure that control fatigue crack growth. ${ }^{[23,53-55]}$ From the viewpoint of plasticity-induced crack closure, ${ }^{[53]}$ it follows from this discussion that the amount of plastic deformation (plastic zone size) at the maximum load, $P_{\text {max }}$, is smaller in the presence of hydrogen than in its absence. Figures 10(a) and (b) illustrate the effect of hydrogen on the crack closure mechanism during one load cycle. Figure 10(a-2) shows the crack opening behavior on the way to the maximum load in the absence of hydrogen. The CTOD reaches its saturated value at a given load level, and crack growth ceases. As shown in Figure 10(b-2), however, hydrogen concentrates near the crack tip in the presence of hydrogen. Hydrogen concentration enhances further crack opening by slip, and crack growth continues. Since the corresponding plastic zone at the crack tip does not become large, the plastic zone wake that remains on the fracture surface is shallow. Figures 10 (c) and (d) are schematic illustrations of plastic zone wakes with and without hydrogen. Ritchie et al. ${ }^{[24,26]}$ pointed out that the reason for the increase in the crack growth rates of a $\mathrm{Cr}-\mathrm{Mo}$ steel in a hydrogen gas environment is the increase in $\Delta K_{\text {eff }}$ due to the absence of oxide-induced crack closure. However, as shown in Figure 10, hydrogen influences all three types of crack closure mechanisms. In particular, the effect of hydrogen on plasticity-induced crack closure is crucially important for all three types of crack closure mechanisms. This phenomenon results both in a decrease in the height of the striation and in a decrease in the crack opening load (decrease in $\Delta K_{o p}$ and increase in $\left.\Delta K_{\text {eff }}\right)$.

As has been described here, a crack grows continuously during loading, in the presence of hydrogen, even before the crack opening displacement reaches its maximum value. Consequently, the crack tip shape at the maximum load is sharper in the presence of hydrogen than in its absence. The effect of hydrogen on plastic deformation at a crack tip may be reduced during unloading. This is because the stress field at the crack tip becomes compressive. Nevertheless, it is presumed that the vertical distance between the peak and the valley of a striation becomes small. This is because the crack opening displacement at the maximum load is small in the presence of hydrogen, even though the amount of reverse slip is the same as that in air. This is the possible mechanism for the small ratio of the striation height, $H$, to the spacing, $s, H / s$, in the presence of hydrogen.

\section{CONCLUSIONS}

The basic mechanism of $\mathrm{HE}$ in the fatigue of austenitic stainless steels of types 304 and 316L has been made clear on the basis of the effects of hydrogen and load frequency on the fatigue crack growth rates. The conclusions can be summarized as follows.

1. Although one of the primary models assumed to explain $\mathrm{HE}$ has been the hydrogen decohesion hypothesis, the basic phenomenon of HE during fatigue loading is not caused by lattice decohesion. The basic mechanism is the diffusion of hydrogen to, and concentration of hydrogen at, crack tips. This leads to the activation of hydrogen-induced slip deformation.

2. Fatigue crack growth rates are increased in the presence of hydrogen, and are strongly dependent on cyclic load frequency. The dependency on load frequency is a consequence of the very low hydrogen diffusion rate in austenitic stainless steels, which have the fcc structure. The local and partial straininduced martensitic transformation at crack tips, which provides the hydrogen diffusion highway, ${ }^{[36,48]}$ also contributes to the concentration of hydrogen.

3. The nondiffusible (irreversible) hydrogen at a level of 2 to approximately $3 \mathrm{wppm}$, trapped at O-sites in the lattice of ordinarily heat-treated austenitic stainless steels, has been ignored for the last 40 years as an important factor causing HE. However, it has been found in the present study that the nondiffusible hydrogen definitely increases fatigue crack growth rates, when the loading frequency is reduced to $0.0015 \mathrm{~Hz}$.

4. If the nondiffusible hydrogen is removed down to the level of $0.4 \mathrm{wppm}$ by a special heat treatment, the damaging influence of the loading frequency disappears, and fatigue crack growth rates are significantly decreased. The special heat treatment (NDH-HT) is a new method of heat treatment that is essentially different from conventional heat treatments such as baking. The new heat treatment method will be useful in improving the material's resistance to $\mathrm{HE}$.

5. The hydrogen-enhanced localized and discrete slip at fatigue crack tips changes the mechanism of crack-opening and closing behavior; as a result, it particularly increases fatigue crack growth rates at a low loading frequency. This mechanism also produces a unique striation morphology in the presence of hydrogen.

\section{ACKNOWLEDGMENTS}

This research has been supported by the NEDO Fundamental Research Project on Advanced Hydrogen Science (2006 to 2012).

\section{APPENDIX}

The effect of cutting thin disks from a sample under water cooling on hydrogen release from the specimen was investigated by measuring the hydrogen content in 
Table AI. Relationship between Hydrogen Content and Disk Thickness for Measurement: Effect of Cutting Disks on Hydrogen Release from Disks ${ }^{[36]}$

\begin{tabular}{lc}
\hline Disk Thickness $(\mathrm{mm})$ & Hydrogen \\
\hline 0.4 & 4.57 \\
0.8 & 4.60 \\
1.6 & 4.42 \\
\hline
\end{tabular}

disk samples with different cutting thickness $(0.4,0.8$, and $1.6 \mathrm{~mm}$ ). A type 304 steel was used in this investigation. The temperature of water was not controlled (approximately room temperature). If hydrogen releases from a specimen by cutting, the hydrogen content of the 0.4-mm-thick disk should have the least value among the three samples. Table AI shows the relationship between the hydrogen content of samples and the sample thickness. There is no evident difference in the three hydrogen contents. Thus, it may be concluded that the present method of determining hydrogen content distribution in a specimen by cutting thin disks can be used with loss of accuracy.

\section{REFERENCES}

1. A.R. Troiano: Trans. ASM, 1960, vol. 52, pp. 54-80.

2. O.A. Oriani and P.H. Josephic: Acta Metall., 1974, vol. 22, pp. $1065-74$.

3. T. Tabata and H.K. Birnbaum: Scripta Metall., 1983, vol. 17, pp. $947-50$.

4. I.M. Robertson and H.K. Birnbaum: Acta Metall., 1986, vol. 34, pp. 353-66.

5. H.K. Birnbaum and P. Sofronis: Mater. Sci. Eng., 1994, vol. A176, pp. 191-202.

6. R.M. Vennett and G.S. Ansell: Trans. ASM, 1967, vol. 60, pp. $242-51$.

7. R.B. Benson, Jr., R.K. Dann, and L.W. Roberts, Jr.: Trans. TMSAIME, 1968, vol. 242, pp. 2199-2205.

8. R. Lagneborg: J. Iron Steel Inst., 1969, vol. 207, pp. 363-66.

9. C.D. Beachem: Metall. Trans., 1972, vol. 3, pp. 437-51.

10. R. Garber, I.M. Bernstein, and A.W. Thompson: Scripta Metall., 1976, vol. 10, pp. 341-45.

11. H. Cialone and R.J. Asaro: Metall. Trans. A, 1979, vol. 10A, pp. $367-75$.

12. D. Eliezer, D.G. Chakrapani, C.J. Altstetter, and E.N. Pugh: Metall. Trans. A, 1979, vol. 10A, pp. 935-41.

13. M. Matsui and H. Kimura: Mater. Sci. Eng., 1979, vol. 40, pp. 207-16.

14. Y. Rosenthal, M.M. Markowitch, A. Stern, and D. Eliezer: Scripta Metall., 1981, vol. 15, pp. 861-66.

15. S. Singh and C. Altstetter: Metall. Trans. A, 1982, vol. 13A, pp. 1799-1808.

16. R.E. Stoltz, N.R. Moody, and M.W. Perra: Metall. Trans. A, 1983, vol. 14A, pp. 1528-31.

17. P. Rozenak, I.M. Robertson, and H.K. Birnbaum: Acta Metall., 1990, vol. 38, pp. 2031-40.

18. P.J. Ferreira, I.M. Robertson, and H.K. Birnbaum: Acta Metall., 1998, vol. 46, pp. 1749-57.

19. A. Valiente, L. Caballero, and J. Ruiz: Nucl. Eng. Des., 1999, vol. 188 , pp. 203-16.

20. M. Nagumo, M. Nakamura, and K. Takai: Metall. Mater. Trans. $A$, 2001, vol. 32A, pp. 339-47.
21. J.D. Frandsen, N.E. Paton, and H.L. Marcus: Scripta Metall., 1973, vol. 7, pp. 409-14.

22. P. Smith and A.T. Stewart: Met. Sci., 1979, vol. 13, pp. 429-35.

23. A.T. Stewart: Eng. Fract. Mech., 1980, vol. 13, pp. 463-78.

24. J. Toplosky and R.O. Ritchie: Scripta Metall., 1981, vol. 15, pp. 905-08.

25. G. Schuster and C. Altstetter: Metall. Trans., 1983, vol. 14A, pp. 2085-90.

26. S. Suresh and R.O. Ritchie: Eng. Fract. Mech., 1983, vol. 18, pp. 785-800.

27. M. Itatani, Y. Miyoshi, and K. Ogura: Eng. Fract. Mech., 1988, vol. 30 , pp. 337-48.

28. S.P. Lynch: Acta Metall., 1988, vol. 36, pp. 2639-61.

29. Y. Katz and W.W. Gerberich: in Hydrogen Effects on Material Behavior: 4th Int. Conf. on the Effect of Hydrogen on the Behavior of Materials, N.R. Moody and A.W. Thompson, eds., TMS, Warrendale, PA, 1990, pp. 469-79.

30. T.J. Marrow, C.A. Hippsley, and J.E. King: Acta Metall., 1991, vol. 39 , pp. $1367-76$.

31. M.H. Kelestemur and T. Chaki: Int. J. Fatigue, 2001, vol. 23, pp. $169-74$.

32. Y. Murakami: Metal Fatigue: Effects of Small Defects and Nonmetallic Inclusions, Elsevier, Oxford, United Kingdom, 2002, pp. 273-303.

33. Y. Murakami and H. Matsunaga: Int. J. Fatigue, 2006, vol. 28, pp. $1509-20$

34. H. Uyama, M. Nakashima, K. Morishige, Y. Mine, and Y. Murakami: Fatigue Fract. Eng. Mater. Struct., 2006, vol. 29, pp. 1066-74.

35. H. Uyama, Y. Mine, and Y. Murakami: J. Soc. Mater. Sci., Jpn., 2006, vol. 55, pp. 726-31.

36. T. Kanezaki, C. Narazaki, Y. Mine, S. Matsuoka, and Y. Murakami: Int. J. Hydrogen Energ., 2007, in press.

37. H. Tanaka, N. Homma, S. Matsuoka, and Y. Murakami: Trans. Jpn. Soc. Mech. Eng. A, 2007, vol. 73, pp. 1358-65.

38. T.P. Perng and C.J. Altstetter: Acta Metall., 1986, vol. 34, pp. $1771-81$

39. S. Xiukui, X. Jian, and L. Yiyi: Acta Metall., 1989, vol. 37, pp. 2171-76.

40. C. Laird: ASTM STP, 1967, vol. 415, pp. 131-68.

41. R.M.N. Pelloux: Trans. ASM, 1969, vol. 62, pp. 281-85.

42. P. Neumann: Acta Metall., 1974, vol. 22, pp. 1155-65.

43. C.H. Bichler and R. Pippan: Engineering Against Fatigue: Int. Conf. on the Importance of Understanding the Fundamentals of the Fatigue Process in Counteracting its Effects in Engineering Components and Structures, J.H. Beynon, M.W. Brown, T.C. Lindley, R.A. Smith and B. Tomkins, eds., Balkema, Rotterdam, 1999, pp. 211-18.

44. Y. Mine, C. Narazaki, T. Kanezaki, S. Matsuoka, and Y. Murakami: J. Iron Steel Inst. Jpn., 2007, vol. 93, pp. 247-56.

45. H.C. Fiedler, B.L. Averbach, and M. Cohen: Trans. ASM, 1955, vol. 47, pp. 267-90.

46. K. Furukawa, Y. Murakami, and S. Nishida: Int. J. Fatigue, 1998, vol. 20 , pp. $509-16$.

47. Y. Fukai: The Metal-Hydrogen System: Basic Bulk Properties, Springer, New York, NY, 1993.

48. Y. Murakami: Proc. Int. Hydrogen Energy Development Forum, Fukuoka, Japan, 2007, pp. 96-105.

49. P. Sofronis and R.M. McMeeking: J. Mech. Phys. Solids, 1989, vol. 37 , pp. $317-50$

50. P. Sofronis, Y. Liang, and N. Aravas: Eur. J. Mech.-A/Solids, 2001, vol. 20, pp. 857-72.

51. Y. Liang, P. Sofronis, and N. Aravas: Acta Mater., 2003, vol. 51, pp. 2717-30.

52. D.C. Ahn, P. Sofronis, and R.H. Dodds, Jr.: Int. J. Hydrogen Energy, vol. 30 , pp. $3734-42$.

53. W. Elber: ASTM STP, 1971, vol. 486, pp. 230-42.

54. R.O. Ritchie, S. Suresh, and C.M. Moss: Trans. ASME, J. Eng. Mater. Technol., 1980, vol. 102, pp. 293-99.

55. K. Minakawa and A.J. McEvily: Scripta Metall., 1981, vol. 15, pp. 633-36. 